\title{
Incidence and Morphology of Accessory Head of Flexor Pollicis Longus in Telangana, India
}

\section{ABSTRACT}

Introduction: Flexor Pollicis Longus (FPL) may have accessory slips which arise from lateral or medial border of coronoid process of ulna and medial epicondyle of humerus. The accessory slip of FPL is known as Accessory Head of Flexor Pollicis Longus (AHFPL) or Gantzer's Muscle.

Aim: To study the incidence and morphology of AHFPL and the relationship of AHFPL with Median Nerve (MN) and Anterior Interosseous Nerve (AIN) in Telangana population.

Materials and Methods: The present study was an observational study, conducted on 25 cadavers ( 21 male, 4 female) for a period of 18 months (July 2019-December 2020) in Department of Anatomy, Osmania Medical College, Hyderabad, Telangana, India. The cadavers which were used for dissection by first year MBBS students were included in the present study and the cadavers with scars, deformities and with congenital anomalies were excluded from the present study.
Results: In the present study, AHFPL was found in 58\% upper limbs. It was bilateral in $40 \%$, unilateral in $18 \%$ upper limbs. The shape of AHFPL was fusiform in majority of (86.2\%) upper limbs. It originated from the coronoid process of ulna in $62 \%$ and from medial epicondyle of humerus in $38 \%$ upper limbs, inserted by joining with tendon of FPL. The AHFPL was innervated by AIN in all the cases and this nerve was located posterior to AHFPL in majority of $(83 \%)$ upper limbs, posterolateral in few $(17 \%)$ upper limbs. The MN was related anterior to the AHFPL in most of the upper limbs.

Conclusion: In the present study, AHFPL was found in 58\% upper limbs. Bilateral occurrence (40\%) was common than unilateral (18\%). The presence of AHFPL can cause AIN syndrome, pronator teres syndrome. The knowledge of AHFPL would be useful for both physicians and surgeons to know the aetiology and management of compression neuropathy/nerve entrapment syndrome.

\section{INTRODUCTION}

The FPL is a recent acquisition in the evolution. It takes origin from the grooved anterior surface of radius and from the adjacent interosseous membrane and gets inserted on to the base of distal phalanx of thumb [1,2]. The FPL is one of the deep flexors of forearm. It is a prime mover of thumb, concerned with precise grasping and stabilise the flexed terminal phalanx of thumb [1].

FPL may have accessory slips which arise from lateral or medial border of coronoid process of ulna and medial epicondyle of humerus. The accessory slip of FPL is known as AHFPL or Gantzer's Muscle [3]. The AHFPL was first described by Carl Friedrich Gantzer in 1813, inserting into FPL/FDP (Flexor Digitorum Profundus) [3].

The AHFPL may cause an entrapment neuropathy of AIN, known as Kiloh-Nevin syndrome/AIN syndrome [4]. This syndrome presents as a weakness in flexion of interphalangeal joint of thumb and distal interphalangeal joint of index and middle finger [4]. The flexor muscles of forearm develop from the flexor mass, which divides into superficial and deep layers. The FPL, FDP muscles originates from the deep layer. Incomplete differentiation of the deep layer of flexor mass during development gives rise to AHFPL [4].

The knowledge of AHFHL is useful for the diagnosis and surgical intervention of nerve entrapment syndrome like AIN syndrome and rarely for carpal tunnel syndrome $[5,6]$. The incidence of AHFPL is variable among different population. It ranges from $24 \%$ to $76.3 \%[3,7,8]$.

In the present study, the authors were concerned with the incidence and morphology of AHFPL and the relationship of AHFPL with MN and AIN in the Telangana population.

\section{MATERIALS AND METHODS}

The present study was an observational study, conducted on 25 cadavers (21 male, 4 female) for a period of 18 months (July 2019December 2020) in Department of Anatomy, Osmania Medical College, Hyderabad, Telangana, India. The study has taken prior approval from Institutional Ethical Committee.

Inclusion criteria: The cadavers which were used for dissection by first year MBBS students were included in the present study.

Exclusion criteria: The cadavers with scars, deformities and with congenital anomalies were excluded from the present study.

\section{Study Procedure}

The dissection was carried out by giving volar incision extending from the distal arm to the palm. Skin was reflected. Superficial fascia, deep fascia was removed. The superficial flexor group of muscles were observed and they were separated from deep flexors. Each forearm was examined carefully to see the presence of AHFPL. Once AHFPL was identified it was studied with respect to incidence, morphology and its relation with $\mathrm{MN}$, anterior osseous nerve.

\section{STATISTICAL ANALYSIS}

The collected data was statistically analysed by using Statistical Package for the Social Sciences (SPSS) 20.0 and expressed as percentages.

\section{RESULTS}

The present study was conducted on 25 cadavers (50 upper limbs) and the results are presented in [Table/Fig-1]. In the present study, AHFPL was found in 58\% (29) upper limbs. It was bilateral in $40 \%$ (20), unilateral in 18\% (9) upper limbs. Among unilateral cases 10\% (5) in the right, 8\% (4) in the left upper limbs were observed. 


\begin{tabular}{l|c|c|c|c|}
\hline \multirow{2}{*}{ Variables } & \multirow{2}{*}{ Bilateral } & \multicolumn{2}{|c|}{ Unilateral } & \multirow{2}{*}{ Rotal } \\
\cline { 3 - 4 } & 20 & 5 & 4 & 29 \\
\hline Number of UL & 40 & 10 & 8 & 58 \\
\hline Percentage & 40 & \multicolumn{4}{l}{} \\
\hline
\end{tabular}

The shape of AHFPL was fusiform in most of (86.2\%) upper limbs [Table/Fig-2,3] and it was slender in few (13.8\%) of upper limbs [Table/Fig-4]. In most of upper limbs (62\%) AHFPL originates from the coronoid process of ulna [Table/Fig-3] and it also takes origin from medial epicondyle of humerus in 38\% upper limbs [Table/Fig-5].

\begin{tabular}{l|c|c|c|c|c|c|}
\hline \multirow{2}{*}{ Variables } & \multicolumn{2}{|c|}{ Shape } & \multicolumn{2}{c|}{ Origin } & \multicolumn{2}{|c|}{ Insertion into FPL } \\
\cline { 2 - 7 } & Fusiform & Slender & $\begin{array}{c}\text { Coronoid } \\
\text { process } \\
\text { of ulna }\end{array}$ & $\begin{array}{c}\text { Medial } \\
\text { epicondyle of } \\
\text { humerus }\end{array}$ & $\begin{array}{c}\text { Upper } \\
1 / 3^{\text {rd }}\end{array}$ & $\begin{array}{c}\text { Middle } \\
1 / 3^{\text {rd }}\end{array}$ \\
\hline Number & 25 & 4 & 18 & 11 & 19 & 10 \\
\hline Percentage & 86.2 & 13.8 & 62 & 38 & 66 & 34 \\
\hline
\end{tabular}
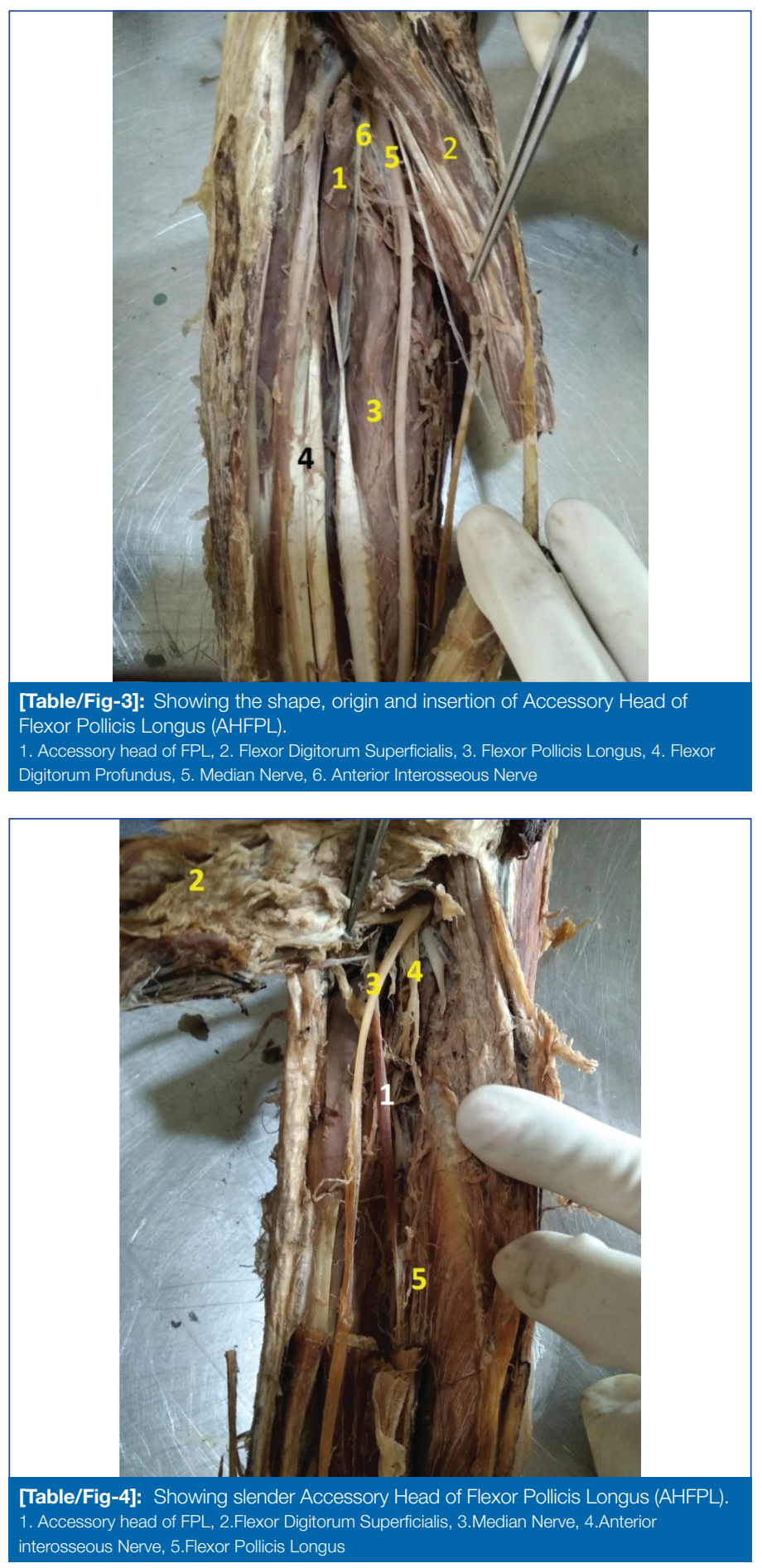

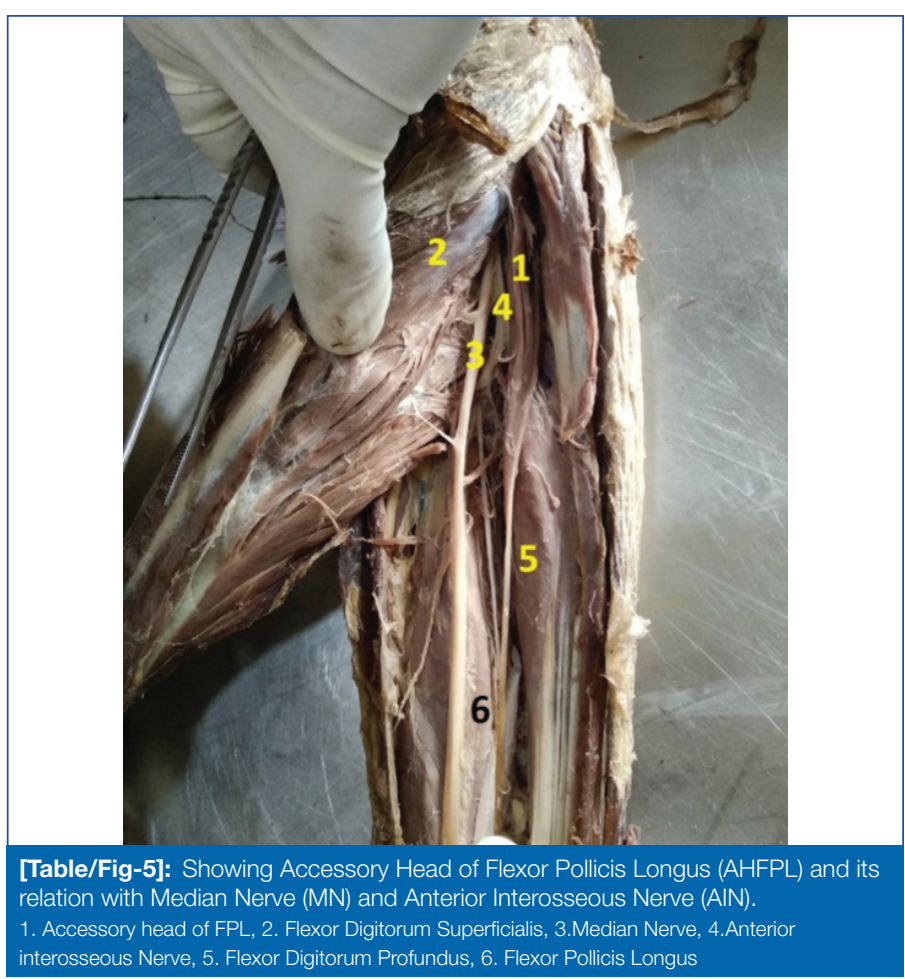

Insertion of AHFPL was by joining with the FPL in upper $1 / 3^{\text {rd }}$ in $66 \%$ [Table/Fig-2] and middle 1/3rd in 34\% upper limbs [Table/Fig-5]. The AHFPL was innervated by AIN in all the cases. The AIN was located posterolateral to AHFPL in 17\% of upper limbs [Table/Fig-4], posterior to AHFPL in 83\% [Table/Fig-5]. The MN was related anterior to the AHFPL in most of the upper limbs (98\%) [Table/Fig-4].

\section{DISCUSSION}

The AHFPL consists of fusiform muscle fibres in opposition to unipennate muscle fibres of FPL and function of fusiform muscle fibres in opposition to unipennate muscle fibres leads to extra strain on the normal functional movement of the FPL and loss of precise, skillful movement [1]. The AHFPL may compress AIN, lead to paresis/ paralysis of the FPL, FDP of the index finger and cause difficulty in the flexion of interphalangeal joint of thumb, distal interphalangeal joint of index finger and in making ' $O$ ' using thumb and index finger which is known as spinner's sign [2].

The incidence of AHFPL was variable among different population [Table/Fig-6] [2-15]. Highest incidence was reported by Jadhav SD and Zambare BR and Hemmady MV et al., [8,15], and lowest reported by Afroz MKH et al., and Sembian $U$ et al., [3,11]. In our study, the incidence of AHFPL was 58\%, these results were close to the results of previous studies done by Khade B et al., Desai RR et al., and Mahakkanukrauh P et al., [2,6,14].

\begin{tabular}{|c|c|c|c|c|c|}
\hline \multirow{2}{*}{$\begin{array}{l}\text { S. } \\
\text { No. }\end{array}$} & \multirow[b]{2}{*}{ Author and Year } & \multirow[b]{2}{*}{ Population } & \multirow{2}{*}{$\begin{array}{l}\text { Sample } \\
\text { size }\end{array}$} & \multicolumn{2}{|c|}{ Incidence } \\
\hline & & & & Number & Percentage \\
\hline 1. & $\begin{array}{l}\text { Khade B et al., } \\
2020 \text { [2] }\end{array}$ & Maharashtra & 60 & 32 & 53 \\
\hline 2. & $\begin{array}{l}\text { Afroz MKH et al., } \\
2020 \text { [3] }\end{array}$ & Karnataka & 50 & 12 & 24 \\
\hline 3. & $\begin{array}{l}\text { Ballesteros DR } \\
\text { et al., } 2018 \text { [4] }\end{array}$ & Colombia & 106 & 34 & 32 \\
\hline 4. & $\begin{array}{l}\text { Rani SB et al., } \\
2017[5]\end{array}$ & Tamilnadu & 50 & 24 & 48 \\
\hline 5. & $\begin{array}{l}\text { Desai RR et al., } \\
2017 \text { [6] }\end{array}$ & Maharashtra & 60 & 35 & 58.3 \\
\hline 6. & $\begin{array}{l}\text { Caetano EB et al., } \\
2015 \text { [7] }\end{array}$ & Brazil & 80 & 54 & 68 \\
\hline 7. & $\begin{array}{l}\text { Jadhav SD, } \\
\text { Zambare BR } \\
2015[8]\end{array}$ & Maharashtra & 114 & 87 & 76.3 \\
\hline
\end{tabular}




\begin{tabular}{|l|l|c|c|c|c|}
\hline 8. & $\begin{array}{l}\text { Gunnal SA et al., } \\
2013 \text { [9] }\end{array}$ & Maharashtra & 180 & 92 & 51 \\
\hline 9. & $\begin{array}{l}\text { Tamang BK et al., } \\
2013 \text { [10] }\end{array}$ & Sikkim & 60 & 26 & 43.3 \\
\hline 10. & $\begin{array}{l}\text { Sembian U et al., } \\
\text { 2012 [11] }\end{array}$ & Chennai & 200 & 02 & 02 \\
\hline 11. & $\begin{array}{l}\text { Sharma M et al., } \\
\text { 2008 [12] }\end{array}$ & Punjab & 60 & 24 & 40 \\
\hline 12. & $\begin{array}{l}\text { Uyaroglu FG et } \\
\text { al., 2006 [13] }\end{array}$ & Turkey & 52 & 27 & 51.9 \\
\hline 13. & $\begin{array}{l}\text { Mahakkanukrauh } \\
\text { P et al., 2004 [14] }\end{array}$ & Thai & 240 & 149 & 62.1 \\
\hline 14. & $\begin{array}{l}\text { Hemmedy MV et } \\
\text { al., 1993 [15] }\end{array}$ & Maharashtra & 54 & 35 & 66.6 \\
\hline 15. & $\begin{array}{l}\text { Present study } \\
\text { 2021 }\end{array}$ & Telangana & 50 & 29 & 58 \\
[Table/Fig-6]: Incidence of AHFPL reported by various authors [2-15]. \\
\hline
\end{tabular}

\section{Limitation(s)}

The sample size was limited (50) and concentrated on incidence, morphology, relation of AHFPL with median and AIN. It will be beneficial to conduct similar studies with larger sample size.

\section{CONCLUSION(S)}

In the present study AHFPL was found in 58\% upper limbs. Bilateral occurrence (40\%) was common than unilateral (18\%). The present study throws light on the importance of AHFPL as it is relevant for the compression neuropathy/nerve entrapment syndrome. The precise anatomical knowledge of AHFPL would be useful for the surgeons, Orthopedicians during decompressive fasciotomies for compartment syndrome.

\section{Acknowledgement}

Authors would like to thank all who donated their bodies and students for participating in the cadaveric dissection process.

In this study, the shape of AHFPL was fusiform in most of the limbs (86.2\%), and it was slender only in few limbs (13.8\%). These observations were in accordance with the observations of studies done by Gunnal SA et al., Tamang BK et al., [9,10].

The origin of AHFPL in the present study was mostly from coronoid process of ulna (62\% of upper limbs) than from medial epicondyle of humerus. Our findings were in accordance with the findings of Jadhav SD and Zambare BR and Sharma M et al., [8,12]. In the present study, it was found that the insertion of AHFPL was mainly with the upper $1 / 3^{\text {rd }}$ of FPL (66\%) than middle $1 / 3^{\text {rd }} \mathrm{FPL}$. Most of the authors reported the same $[4,6,8]$.

The AHFPL was supplied by AIN in all cases and the nerve was posterior to the AHFPL in most of the cases (83\%). These findings were in accordance with the findings of several studies done by Afroz MKH et al., Gunnal SA et al., Hemmady MV et al., $[3,9,15]$, Repetitive trauma to the forearm and structural anomalies and cicatricle contraction of AHFPL as in Volkmann Ischemic Contracture can lead to entrapment of AIN and MN. Paralysis of AIN due to compression in the forearm is also known as the KilohNevin syndrome [9]. The presence of AHFPL has to be kept in mind during anterior approaches to the proximal radius and elbow joint as decompressive fasciotomy for compartment syndrome of forearm [15]. Precise knowledge of AHFPL muscle is necessary while doing the diagnosis and surgeries of various compartment syndromes of forearm.

The advancement of new imaging techniques such as Computed Tomography (CT) and Magnetic Resonance Imaging (MRI) are helpful to detect the anatomical variation and abnormalities of the muscles of forearm. These techniques should be used before surgery for better outcome and to prevent iatrogenic trauma during surgeries.

\section{REFERENCES}

[1] Mani SS, Vishnumaya G, Madhan Kumar SJ. Accessory head of flexor pollicis longus and its significance in anterior interosseus nerve neuropathies and precision handling clinical entity. Int J Anat Var. 2010;3:46-48.

[2] Khade B, Choudhari G, Yadav N, Mangalgiri A. Anatomical study of accessory head of flexor pollicis longus and its clinical significance. Nat J Clin Aant. 2020;9(4):151-54.

[3] Afroze MKH, Umesh SN, Sangeeta M, Varalakshmi KL, Suman T. An anatomical and morphological study on accessory Head of flexor pollicis longus (Gantzer's muscles) and its clinical emphasis. Int J Anat Res. 2020;8(2.3):7568-71.

[4] Ballesteros DR, Forero PL, Ballesteros LE. Accessory head of the flexor pollicis longus muscle: Anatomical study and clinical significance. Folia Morphol. 2018;78(2):394-400

[5] Rani SB, Sunitha NS, Karpagajothi J. Study of accessory head of flexor pollicis longus in south Indian population. IOSR-JDMS. 2017;16(5):36-40.

[6] Desai RR, Desai AR, Ambali MP. Incidence of accessory head of flexor pollicis longus (only in males) and its clinical significance. National Journal of Integrated Research in Medicine. 2017;8(1):88-91.

[7] Caetano EB, Sobongi JJ, Vieira LA, Caetano MF, Moraes DV. Gantzer muscle. An anatomical study. Acta Ortop Bras. 2015;23(2):72-75.

[8] Jadhav SD, Zambare BR. Accessory head of flexor pollicis longus muscle and its clinical significance. International Journal of Current Research. 2015;7(5):1654016543.

[9] Gunnal SA, Siddiqui AU, Daimi SR, Farooqui MS, Wabale RN. Study on the accessory head of the flexor pollicis longus muscle (Gantzer's Muscle). J Clin Diagn Res. 2013;7(3):418-21.

[10] Tamang BK, Sinha P, Sarda RK, Shailo P, Murlimanju BV. Incidence and morphology of accessory head of flexor pollicis longus muscle-an anatomical study. J Evol Med Dental Sci. 2013;2(36):6800-06.

[11] Sembian U, Srimathi T, Muhil M, Nalina Kumari SD, Subramanian T. A study of the accessory muscles in the flexar compartment of forearm. J Clin Diagn Res. 2012;6:564-67.

[12] Sharma M, Chabbra U, Kaushal S. Accessory head of flexor pollicis longus muscle. J Exerc Sci Physiother. 2008;4:15-18.

[13] Uyarogulu FG, Kayalioglu G. Erturk M. Incidence and morphology of the accessory head of the flexor pollicis longus muscle(Gantzer's muscle) in a Turkish population. Neurosciences. 2006;11(3):171-74.

[14] Mahakkanukrauh $P$, Surin $P$, Ongkana N, Sethadavit M, Vaidhayakarn P. Prevalence of accessory head of flexor pollicis longus muscle and its relation to anterior interosseous nerve in Thai population. Clin Anat. 2004;17:631-35.

[15] Hemmady MV, Subramanya AV, Mehta IM. Occasional head of flexor pollicis longus muscle: A study of its morphology and clinical significance. J Postgrad Med. 1993;39(1):14-16.

\section{PARTICULARS OF CONTRIBUTORS:}

1. Professor and Head, Department of Anatomy, Government Medical College, Siddipet, Telangana, India

2. Assistant Professor, Department of Anatomy, Osmania Medical College, Hyderabad, Telangana, India.

NAME, ADDRESS, E-MAIL ID OF THE CORRESPONDING AUTHOR: Niveditha Samala,

House No. 5-84/1, Shanthi Nagar Colony, Hydershakote, Rajendra Nagar,

Ranga Reddy District, Hyderabad-500091, Telangana, India.

E-mail: snivedithak@gmail.com
PLAGIARISM CHECKING METHODS: Jain Het al.

- Plagiarism X-checker: Jan 18, 2021

- Manual Googling: Mar 18, 2021

- iThenticate Software: Apr 24, 2021 (23\%)

\section{AUTHOR DECLARATION}

- Financial or Other Competing Interests: None

- Was Ethics Committee Approval obtained for this study? Yes

- Was informed consent obtained from the subjects involved in the study? NA

- For any images presented appropriate consent has been obtained from the subjects. NA

Date of Submission: Jan 16, 2021 Date of Peer Review: Feb 16, 2021 Date of Acceptance: Mar 19, 2021

Date of Publishing: Jul 01, 2021 